\title{
CHEMICAL PROFILE AND ANTIBACTERIAL ACTIVITY OF ESSENTIAL OILS FROM LEAVES AND FRUITS OF GAULTHERIA PROCUMBENS L. CULTIVATED IN POLAND
}

\author{
ANNA MAGIERA ${ }^{1 *}$, MONIKA SIENKIEWICZ ${ }^{2}$, MONIKA A. OLSZEWSKA', \\ AGNIESZKA KICEL ${ }^{1}$ and PIOTR MICHEL ${ }^{1}$
}

${ }^{1}$ Department of Pharmacognosy, Faculty of Pharmacy, Medical University of Lodz,

1 Muszyńskiego St., 90-151 Łódź, Poland

${ }^{2}$ Department of Allergology and Respiratory Rehabilitation, Faculty of Military Medicine, Medical University of Lodz, 1 Hallera Sq., 90-647 Łódź, Poland

\begin{abstract}
Essential oils (EOs) of Gaultheria procumbens were obtained by hydrodistillation with the yield of $1.30 \% \pm 0.05(v / d w)$ for leaves and 2.68\% $\pm 0.08(v / d w)$ for fruits. The GC-FID/MS analysis led to the identification of 64 volatile components, among which 27 were found in leaf EO, 49 in fruit EO, and 59 analytes were detected for the first time in G. procumbens. Methyl salicylate, which is known as a potent anti-inflammatory agent, was the dominant component making up to $97.5 \%$ and $99.8 \%$ of the total fruit and leaf EOs, respectively. The remaining volatiles of the leaves included mainly monoterpenes ( $\alpha$-pinene, $\beta$-pinene, limonene), methyl-o-anisate, massoilactone, spiro[4,5]decane-1-one, and aliphatic alcohols (heptan-2-ol, octan-1-ol), while the fruit EO contained apart from the dominant aliphatic and aromatic alcohols (benzyl alcohol, heptan2-ol, p-cymen-7-ol) also carboxylic acids (3-hydroxyphenylacetic acid, heptanoic acid, octanoic acid) and aldehydes (hexanal, furfural, pent-4-enal). The antibacterial activity of the EOs was evaluated using a microdilution broth method against twelve reference strains, as well as clinical and environmental isolates. Differences between activity parameters of both EOs were not statistically significant $(\mathrm{p}>0.05)$ for most tested bacteria. On the other hand, both EOs were significantly more effective against Gram-negative (MIC, 8.2-10.0 mg/mL) than Gram-positive bacteria (MIC, $13.5-16.7 \mathrm{mg} / \mathrm{mL}$ ). Leaves and especially fruits of $G$. procumbens cultivated in Poland were proved valuable sources of methyl salicylate-rich EOs of moderate antibacterial activity, which, therefore, could partly explain the traditional use of the plant materials and the EOs in the treatment of bacterial infections-related inflammatory disorders.
\end{abstract}

Keywords: Gaultheria procumbens L., essential oil, GC-FID/MS analysis, chemical composition, methyl salicylate, antibacterial activity

Essential oils are natural, plant-derived multicomponent mixtures of low-molecular organic compounds characterized by an intense scent, high volatility, and lipophilicity. Nowadays, they are used in many industries, including the food industry - as natural flavouring substances, as well as in cosmetics, perfumery and pharmaceutical industries as ingredients of syrups, tablets, ointments, and inhalation fluids applied to relieve several pathological conditions like spasmodic coughs, cold symptoms, chest congestion, sinus infections, breathing problems, asthma, and dermatological infections (13). Numerous experimental studies have shown that essential oils demonstrate a large spectrum of pharmacological activities. Among others, they are known for antiseptic, i.e. antibacterial, antiviral, and antifungal properties (4). Herbal essential oils have also been reported to exhibit anti-inflammatory and immunostimulatory potential. The wide spectrum of biological activities forms a basis for the use of volatile oils in the prevention and treatment of infectious human disorders, especially respiratory tract diseases and skin problems $(5,6)$.

Gaultheria procumbens L., also known as eastern teaberry, checkerberry, boxberry, or American wintergreen, is an aromatic plant of family Ericaceae, native to North America and cultivated all through the northern hemisphere due to its decorative qualities and medicinal value. G. procumbens is a small, low-growing, evergreen shrub with creep-

* Corresponding author: e-mail: anna.magiera@stud.umed.lodz.pl 
ing shoots, white or pink bell-shaped flowers and red berry-like fruits (7). In traditional medicine, leaves and fruits of the eastern teaberry and other Gaultheria species have been used for hundreds of years as an anti-inflammatory, analgesic and antipyretic remedy, in the treatment of influenza, cough, asthma, rheumatoid arthritis, pain of various etiology, and in wound healing (8). The anti-inflammatory activity of these plants is believed to be influenced mainly by salicylic acid derivatives, especially methyl salicylate prevailing in essential oils $(9,10)$ and its glycosidic precursor gaultherin (11) found in fresh plant materials. The essential oils of Gaultheria species have also been reported as antimicrobial agents, mainly antibacterial and antifungal $(9,10,12-17)$, and this activity might be crucial for understanding the traditional applications of the respective herbal products in microbial infections-related ailments.

The volatile oils produced by plants of the genus Gaultheria are often called "wintergreen oils", regardless of the plant species and parts (rhizomes, stems, leaves and sometimes whole plants) used in the distillation process (8). The average content of the essential oil in the species studied so far (G. fragrantissima Wahl.) is noticeable and ranges from $0.7 \%$ to $1.8 \%(v / d w)$ of the biomass $(18,19)$. However, the potential of numerous species, including $G$. procumbens, in terms of the essential oil accumulation remains underestimated. There is also little information on differences in distillation yield as well as in chemical and activity profiles of the essential oils obtained from various plant tissues, as well as among plants cultivated in different environments (e.g. in different geographic regions), although it is well known that several environmental factors and climatic conditions may significantly affect the qualitative and quantitative composition of essential oils, and thereby, their biological activity (20). In the case of G. procumbens, previous studies on the chemical composition and biological activity of wintergreen oil concerned only plants cultivated in southern Europe and Asia $(9,13,21)$.

For this reason, the aim of the present research was to estimate the chemical composition and antibacterial activity of the essential oils obtained from $G$. procumbens cultivated in Poland. The essential oils were distilled separately from leaves and fruits plant parts the most frequently recommended by ethnobotanical sources. The phytochemical profiles of the volatile oils were thoroughly investigated by GC-FID/MS with the use two capillary columns of different selectivity, while the antibacterial activity was tested by a microdilution broth method against several reference strains and isolates obtained from patients and from hospital equipment.

\section{MATERIALS AND METHODS}

\section{Plant material}

Leaves and fruits of $G$. procumbens L. were collected in October 2016 in the nursery-garden of Ericaceae plants, Gospodarstwo Szkolkarskie Jan Cieplucha (54\%44' N, 19¹8' E), Konstantynow Lodzki, Poland, where the plants grew in an open area. The seeds for the nursery were imported from the William J. Beal Botanical Garden (Michigan State University, East Lansing, MI, USA), and authenticated by Piotr Banaszczak, Head of the Arboretum, Forestry Experimental Station of Warsaw University of Life Sciences (SGGW) in Rogow, Poland. The voucher specimen was deposited in the herbarium of the Department of Pharmacognosy, Medical University of Lodz, Poland, and bore number KFG/HB/17001-GPRO. Leaf and fruit samples were collected from randomly selected individual healthy plants, separated for minimum $5 \mathrm{~m}$ and representing the average development stage at the sampling site.

\section{Essential oil isolation}

Triplicate samples of fresh leaves $(150 \mathrm{~g})$ and fruits $(150 \mathrm{~g})$ of $G$. procumbens L. were hydrodistilled separately for three hours using a Dean\&Stark apparatus. The obtained essential oils were dried with anhydrous sodium sulfate and stored at $4^{\circ} \mathrm{C}$ until analyzed. The isolation yield was reported in terms of volume/weight $(v / w)$ percentage content of the essential oils $(\mathrm{mL})$ in the dry weight $(100 \mathrm{~g})$ of the plant material.

\section{Essential oil profiling}

The GC-FID/MS analyses of the essential oils were performed using a Trace GC Ultra apparatus (Thermo Electron Corporation, USA) coupled with FID and MS DSQ II detectors. Simultaneous GCFID and GC-MS experiments were performed using a FID-MS splitter (SGE Analytical Science, UK). The conditions for analysis were as follows: a nonpolar capillary column Rtx-1 MS (Restek, USA), $60 \mathrm{~m} \times 0.25 \mathrm{~mm}$ i.d., film thickness $0.25 \mu \mathrm{m}$, temperature program: $50-300^{\circ} \mathrm{C}(30 \mathrm{~min})$ at $4^{\circ} \mathrm{C} / \mathrm{min}$, injector temperature $280^{\circ} \mathrm{C}$, detector (FID) temperature $300^{\circ} \mathrm{C}$, carrier gas helium, constant pressure $300 \mathrm{kPa}$; a polar capillary column TGWax-Gold (Thermo Scientific, USA), $30 \mathrm{~m} \times 0.25 \mathrm{~mm}$ i.d., film thickness $0.25 \mu \mathrm{m}$, temperature program: 50 $240^{\circ} \mathrm{C}(30 \mathrm{~min})$ at $4^{\circ} \mathrm{C} / \mathrm{min}$, injector and detector 
temperatures were $250^{\circ} \mathrm{C}$ and $260^{\circ} \mathrm{C}$, respectively, carrier gas helium at a flow rate of $0.8 \mathrm{~mL} / \mathrm{min}$. Mass spectra were acquired over the mass range 30 $400 \mathrm{Da}$, ionization energy was $70 \mathrm{eV}$, and ion source temperature was set at $200^{\circ} \mathrm{C}$.

\section{Identification of volatile components}

The identification of the essential oils constituents was based on the comparison of their retention indices (RI) on both nonpolar and polar columns (relative to $n$-alkanes $\mathrm{C}_{8}-\mathrm{C}_{26}$ ) and mass spectra (MS) with computer mass library NIST 08, Wiley Registry of Mass Spectral Data $8^{\text {th }}$ Edn., and Mass Finder 4.1 library. Quantitative determination of the individual components was carried out by GC peak area normalization without the use of correction factors.

\section{Antibacterial activity studies}

The antibacterial activity was assessed against Gram-positive and Gram-negative reference strains: Staphylococcus aureus ATCC 29213, Enterococcus faecalis ATCC 29212, Escherichia coli ATCC 25922, and Acinetobacter baumannii ATCC 19606, as well as against eight bacterial isolates obtained from patients treated in various wards (internal diseases, surgery, urology, and intensive care units) and the environment from one of the Medical University hospitals in Lodz. Bacteria were cultured on Columbia Agar (bioMerieux, France), Mannitol Salt Agar (bioMerieux, France), Enterococcosel Agar (Emapol, Poland), Mac Conkey Agar (bioMerieux, France). They were identified with the use of API Staph, API 20 Strep, API 20 E and API 20 NE tests (bioMerieux, France) and by VITEK 2 (bioMerieux, France) system. The antibacterial activity of the tested essential oils was assessed with the use of a microdilution broth method and expressed as values of Minimal Inhibitory Concentration (MIC). The reference strains, clinical isolates and environmental bacteria were cultivated on Columbia Agar medium and incubated at $37^{\circ} \mathrm{C}$ for 24 hours. Bacterial suspensions with an optical density of $0.5 \mathrm{MF}$ scale were prepared with a bioMerieux densitometer (France). The tested essential oils were diluted in DMSO (SigmaAldrich, Germany/USA) yielding concentration of $95 \%(v / v)$ of the essential oils. This stock solution was mixed with $100 \mu \mathrm{l}$ Mueller-Hinton Broth (Graso, Poland) to obtain concentrations from 8.2 to $16.7 \mathrm{mg} / \mathrm{mL}$ and transferred to 96 -well microtiter plates. An inoculum containing $1.5 \cdot 10^{8} \mathrm{CFU}(10 \mu \mathrm{L})$ per well was added to a broth with various essential oil concentrations. The MIC was determined as the lowest concentration of the volatile oil which inhibits visible growth of bacteria after 24 hours of incubation at $37^{\circ} \mathrm{C}$ under aerobic conditions. The control media containing only DMSO did not inhibit the growth of bacteria. The susceptibility to recommended antibiotics for all clinical isolates and environmental strains was determined through a standard disc-diffusion method of Kirby-Bauer (22). Obtained inhibition-zone results were compared with the guidelines of the European Committee on Antibacterial Susceptibility Testing (23).

\section{RESULTS AND DISCUSSION}

Hydrodistilled essential oils of G. procumbens leaves and fruits were pale-yellow liquids, having a powerful salicylic aroma and bitter-sweet taste. The fruit samples were found to accumulate significantly $(\mathrm{p}<0.05)$ higher content of the essential oil $(2.68 \% \pm 0.08, v / d w)$ than the analyzed leaves $(1.30 \% \pm 0.05, v / d w)$. The obtained value for $G$. procumbens leaf essential oil stands generally in accordance with the yields $(0.70-1.79 \%, v / d w)$ reported previously for essential oil distilled from leaves of $G$. fragrantissima (18, 19). However, according to our best knowledge, there is no literature data on the content of essential oils distilled from any part of G. procumbens, and previous works refer only to their chemical and biological profiles $(9,13,21)$.

The chemical composition of the tested volatile oils was analyzed by GC-FID/MS, which resulted in the identification of sixty four components, constituting $99.24 \%$ and $100.00 \%$ of the total fruit and leaf essential oils, respectively, among which fifty nine compounds were recognized for the first time in $G$. procumbens (Table 1). With forty nine analytes identified, the qualitative composition of the fruit essential oil was more complex in comparison to the essential oil from leaves, in which only twenty seven volatiles were found. Methyl salicylate was the prevalent constituents of both essential oils comprising $99.76 \%$ and $97.47 \%$ of the leaf and fruit volatile fractions, respectively. Apart from this constituent, only eleven further volatiles were found in both essential oils, including hex-3-en-1-ol, heptan2-ol, limonene, nonanal, linalool, massoilactone, $p$ cymene, octanal, hexan-1-ol, oct-1-en-3-ol and octan-1-ol, which suggested that the GC-profiles of the essential oils are strongly plant-part-specific.

Besides the dominant component, the leaf volatile fraction was characterized by the presence of monoterpenes and aliphatic alcohols (Table 1, Figure 1A). The major monoterpenes were $\alpha$-pinene 
Table 1. Composition of the leaf and fruit essential oils of G. procumbens.

\begin{tabular}{|c|c|c|c|c|c|c|c|}
\hline & Constituent & $\mathrm{KI}_{\mathrm{E}} \mathrm{Rtx}-1$ & $\mathrm{KI}_{\mathrm{L}}$ (nonpolar) & $\mathrm{KI}_{\mathrm{E}}$ TGWAX & $\mathrm{KI}_{\mathrm{L}}$ (polar) & Leaf EO & Fruit EO \\
\hline 1. & Pent-1-en-3-ol* & 672 & 671,674 & 1162 & 1158,1161 & - & $\operatorname{tr}$ \\
\hline 2. & Pentanal* & 676 & 674,678 & 992 & 984,992 & - & $\operatorname{tr}$ \\
\hline 3. & Pent-4-enal* & 727 & - & 1147 & 1134 & - & 0.01 \\
\hline 4. & Pentan-1-ol* & 750 & 744,749 & 1254 & 1251,1255 & - & $\operatorname{tr}$ \\
\hline 5. & Hexanal* & 777 & 775,780 & 1094 & 1091,1092 & - & 0.03 \\
\hline 6. & Furfural* & 804 & 802,804 & 1482 & 1483,1486 & - & 0.03 \\
\hline 7. & (E)-hex-2-enal* & 823 & 824,827 & 1235 & 1231,1232 & $\operatorname{tr}$ & - \\
\hline 8. & 4-methylhex-5-en-2-ol* & 825 & - & 1348 & - & - & 0.02 \\
\hline 9. & Hex-3-en-1-ol* & 844 & 841,843 & 1390 & 1390,1391 & $\operatorname{tr}$ & $\operatorname{tr}$ \\
\hline 10. & Hex-2-en-1-ol* & 849 & 849,850 & 1413 & 1411,1412 & $\operatorname{tr}$ & - \\
\hline 11 & Hexan-1-ol* & 850 & - & 1357 & 1357,1359 & $\operatorname{tr}$ & $\operatorname{tr}$ \\
\hline 12. & Santene* & 878 & 884,888 & - & - & $\operatorname{tr}$ & - \\
\hline 13. & Heptanal* & 880 & 878,880 & 1197 & 1197,1199 & - & $\operatorname{tr}$ \\
\hline 14. & Heptan-2-ol* & 887 & 886,887 & 1323 & 1323,1324 & 0.02 & 0.07 \\
\hline 15. & $\alpha$-pinene & 928 & 926,930 & - & - & 0.04 & - \\
\hline 16. & $\begin{array}{l}(S) \text {-2-ethyl-4-methyl- } \\
\text { pentan-1-ol* }\end{array}$ & 931 & - & 1515 & 1506 & $\operatorname{tr}$ & - \\
\hline 17. & Hept-2-enal* & 935 & 930,937 & 1341 & 1339,1342 & - & $\operatorname{tr}$ \\
\hline 18. & Camphene* & 941 & 941,943 & - & - & $\operatorname{tr}$ & - \\
\hline 19. & Heptan-1-ol* & 952 & 952,954 & 1460 & 1458,1460 & - & $\operatorname{tr}$ \\
\hline 20. & Oct-4-en-3-one* & 954 & 956 & 1315 & 1303 & - & $\operatorname{tr}$ \\
\hline 21. & Benzaldehyde* & 963 & 961,965 & 1548 & 1549 & - & 0.01 \\
\hline 22. & $\beta$-pinene & 968 & 965,975 & 1114 & 1113,1115 & 0.01 & - \\
\hline 23. & 6-methylhept-5-en-2-ol* & 976 & 974,976 & 1467 & 1466,1467 & - & $\operatorname{tr}$ \\
\hline 24. & Oct-1-en-3-ol* & 978 & 971,982 & 1454 & 1453,1454 & $\operatorname{tr}$ & $\operatorname{tr}$ \\
\hline 25. & 2-pentylfuran* & 981 & 980,984 & 1239 & 1238,1239 & - & 0.01 \\
\hline 26. & Octanal* & 983 & 982,984 & 1300 & 1301,1302 & $\operatorname{tr}$ & $\operatorname{tr}$ \\
\hline 27. & 2-methylhept-6-en-1-ol* & 985 & - & 1468 & 1468,1469 & $\operatorname{tr}$ & - \\
\hline 28. & Octa-3,5-dien-2-ol* & 995 & - & 1424 & - & - & $\operatorname{tr}$ \\
\hline 29. & 2-ethylhexan-1-ol* & 1018 & 1015,1020 & 1494 & 1491,1492 & - & $\operatorname{tr}$ \\
\hline 30. & Limonene & 1020 & 1031 & 1208 & 1209,1210 & 0.01 & 0.01 \\
\hline 31. & $p$-cymene* & 1021 & 1020,1022 & 1280 & 1279,1281 & 0.01 & $\operatorname{tr}$ \\
\hline 32. & Benzyl alcohol* & 1032 & 1026,1033 & 1891 & - & - & 0.55 \\
\hline 33. & Oct-2-enal* & 1037 & 1035,1039 & 1446 & 1442,1447 & - & $\operatorname{tr}$ \\
\hline 34. & Octan-1-ol* & 1059 & 1054,1057 & 1566 & 1565,1566 & 0.01 & 0.01 \\
\hline 35. & Octa-3,5-dien-2-one* & 1064 & 1063 & 1540 & 1539 & - & $\operatorname{tr}$ \\
\hline 36. & Sabinene & 1070 & 1068,1070 & 1112 & 1111,1114 & - & $\operatorname{tr}$ \\
\hline 37. & Heptanoic acid* & 1073 & 1065,1074 & 1962 & 1963,1965 & - & 0.37 \\
\hline 38. & Nonanal* & 1084 & 1079,1083 & 1405 & 1402,1406 & $\operatorname{tr}$ & 0.01 \\
\hline 39. & Nonan-2-ol* & 1085 & 1084,1085 & 1525 & 1524,1528 & - & 0.01 \\
\hline 40. & Linalool* & 1090 & 1087,1090 & 1556 & 1557,1558 & $\operatorname{tr}$ & 0.01 \\
\hline 41. & Borneol* & 1138 & - & 1709 & 1706,1707 & - & $\operatorname{tr}$ \\
\hline 42. & Naphthalene* & 1148 & 1146,1148 & 1765 & 1763,1765 & - & 0.01 \\
\hline 43. & Nonan-1-ol* & 1151 & 1151,1154 & 1654 & 1652,1675 & $\operatorname{tr}$ & - \\
\hline
\end{tabular}


Table 1. Continued.

\begin{tabular}{|c|c|c|c|c|c|c|c|}
\hline & Constituent & $\mathrm{KI}_{\mathrm{E}}$ Rtx-1 & $\mathrm{KI}_{\mathrm{L}}$ (nonpolar) & $\mathrm{KI}_{\mathrm{E}} \mathrm{TGWAX}$ & $\mathrm{KI}_{\mathrm{L}}$ (polar) & Leaf EO & Fruit EO \\
\hline 44. & Octanoic acid* & 1163 & 1162,1165 & 2069 & 2069,2072 & - & 0.08 \\
\hline 45. & Isopinocarveol* & 1177 & 1176 & 1668 & - & - & 0.01 \\
\hline 46. & $\beta$-cyclocitral* & 1195 & 1194,1196 & 1642 & 1638 & $\operatorname{tr}$ & - \\
\hline 47. & Methyl salicylate & 1221 & 1217,1236 & 1817 & 1787,1803 & 99.76 & 97.47 \\
\hline 48. & Dec-3-en-1-ol* & 1237 & - & 1517 & - & - & 0.01 \\
\hline 49. & Nonanoic acid* & - & - & 2174 & 2171,2173 & - & 0.01 \\
\hline 50. & $p$-cymen-7-ol* & 1273 & 1270,1278 & 2113 & 2113,2114 & - & 0.06 \\
\hline 51. & Bornyl acetate* & 1278 & 1272,1282 & - & - & $\operatorname{tr}$ & - \\
\hline 52. & Spiro[4,5]decane-1-one* & 1285 & - & 2318 & - & 0.03 & - \\
\hline 53. & Methyl-o-anisate* & 1297 & 1295,1298 & 2085 & - & 0.07 & - \\
\hline 54. & Eugenol* & 1331 & 1331,1332 & 2182 & 2180,2184 & - & 0.02 \\
\hline 55. & $\begin{array}{l}\text { 2,6-dihydroxybenzoic } \\
\text { acid methyl ester* }\end{array}$ & 1341 & 1340 & 2286 & - & - & 0.02 \\
\hline 56. & Neric acid* & - & - & 2348 & - & - & $\operatorname{tr}$ \\
\hline 57. & Isoeugenol* & 1429 & 1427,1430 & 2367 & 2368 & - & 0.01 \\
\hline 58. & Massoilactone* & 1450 & - & 2258 & - & 0.04 & $\operatorname{tr}$ \\
\hline 59. & $\begin{array}{l}\text { Acetylsalicylic acid } \\
\text { methyl ester* }\end{array}$ & 1452 & - & - & - & $\operatorname{tr}$ & - \\
\hline 60. & 3-hydroxyphenylacetic acid* & 1470 & - & 1925 & - & - & 0.39 \\
\hline 61. & Tridecanedial* & 1690 & - & 1432 & - & - & $\operatorname{tr}$ \\
\hline 62. & Heptadec-13-yn-1-ol* & 1971 & - & 1640 & - & - & $\operatorname{tr}$ \\
\hline 63. & Abieta-8,11,13-triene* & 2043 & 2030,2050 & - & - & $\operatorname{tr}$ & - \\
\hline 64. & $\begin{array}{l}\text { Octadeca-13,16-diynoic } \\
\text { acid methyl ester* }\end{array}$ & 2093 & - & 1501 & - & - & $\operatorname{tr}$ \\
\hline & & & & \multicolumn{2}{|c|}{ Methyl salicylate: } & 99.76 & 97.47 \\
\hline & & & & \multicolumn{2}{|c|}{ Monoterpenes: } & 0.06 & 0.03 \\
\hline & & & & \multicolumn{2}{|c|}{ Aliphatic compounds: } & 0.03 & 0.63 \\
\hline & & & & \multicolumn{2}{|c|}{ Aromatic compounds: } & 0.08 & 1.11 \\
\hline & & & & \multicolumn{2}{|c|}{ Others: } & 0.07 & $\operatorname{tr}$ \\
\hline & & & & \multicolumn{2}{|c|}{ Total identified: } & 100.00 & 99.24 \\
\hline
\end{tabular}

$\mathrm{KI}_{\mathrm{E}} \mathrm{Rtx}-1$, experimental retention index determined on nonpolar column Rtx-1 based on $n$-alkane series; $\mathrm{KI}_{\mathrm{L}}$ (nonpolar), literature Kovats retention index on nonpolar column DB-1 or DB-5; $\mathrm{KI}_{\mathrm{E}} \mathrm{TGWAX}$, experimental retention index determined on polar column TGWAX based on $n$-alkane series; $\mathrm{KI}_{\mathrm{L}}$ (polar), literature Kovats retention index on polar column; Leaf EO and Fruit EO, relative contents in the leaf and fruit essential oils, respectively, expressed as a percentage of the total oil composition: tr, trace amount $<0.01 \%$; compounds identified for the first time in G. procumbens were marked with an asterisk $(*)$.

$(0.04 \%), \beta$-pinene $(0.01 \%)$, and limonene $(0.01 \%)$, whereas heptan-2-ol $(0.02 \%)$ and octan-1-ol $(0.01 \%)$ were the main aliphatic alcohols. The specific feature of the leaf essential oil was a relatively high content of phenyl ester (methyl-o-anisate, $0.07 \%)$, massoilactone $(0.04 \%)$, spiro[4,5]decane-1one $(0.03 \%)$, and alkylbenzene ( $p$-cymene, $0.01 \%)$, as well as $\alpha$ - and $\beta$-pinenes, which were absent or present only in traces in the fruit essential oil.
The qualitative and quantitative composition of the leaf essential oil, reported here for G. procumbens cultivated in Poland, was only partially consistent with the available literature, and the observed differences might be related to both climatic and analytical factors. Previous studies of the essential oils distilled from the leaf material of Asian (Indian) origin $(13,21)$ pointed to a slightly lower content of methyl salicylate $(96.25-96.61 \%)$ and thus higher 
levels of accompanying constituents, especially monoterpenes, with however a less complex pattern of structurally characterized analytes, comprising at most four (13) and seven (21) components, respectively. Out of earlier identified volatiles, including geranial $(0.92-1.11 \%)$, neral $(0.76-1.02 \%)$, diethyl phthalate $(0.42-0.45 \%), \delta$-3-carene $(0.12 \%)$, 4-hydroxy-4-methyl-2-pentanone $(0.10 \%)$, and $\alpha$-pinene $(0.08 \%)$, only $\alpha$-pinene was found in the essential oil of Polish origin. Similarly, in the essential oil
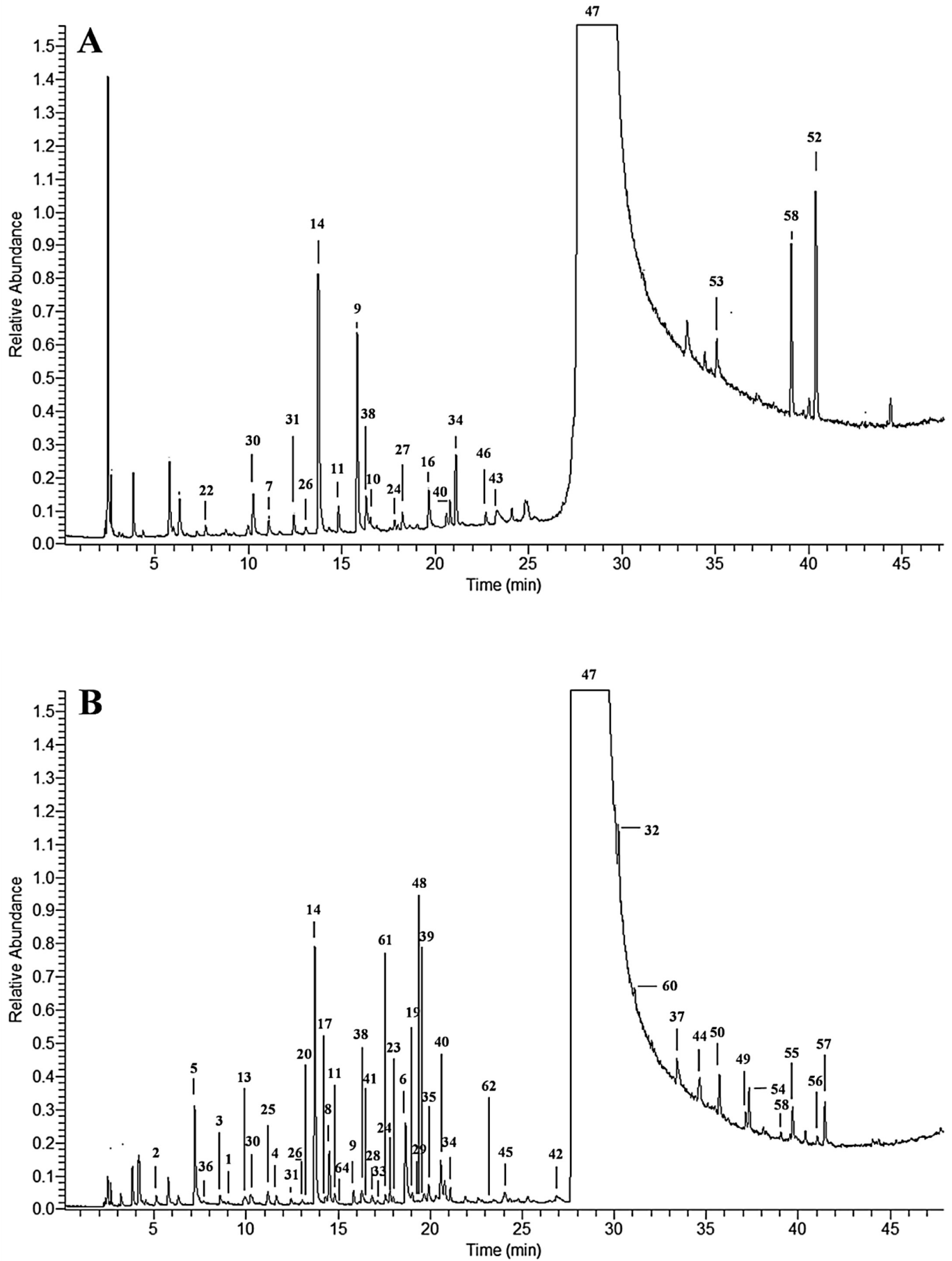

Figure 1. Representative GC-FID/MS chromatograms of essential oils from leaves (A) and fruits (B) of G. procumbens on polar column TGWAX. Peak numbers refer to those implemented in Table 1 
Table 2. Antibacterial activity of the leaf and fruit essential oils of G. procumbens.

\begin{tabular}{|c|c|c|c|c|}
\hline \multirow{2}{*}{ Analyte } & \multicolumn{4}{|c|}{ MIC $(\mathrm{mg} / \mathrm{mL})$} \\
\cline { 2 - 5 } & $\begin{array}{c}\text { Staphylococcus } \\
\text { aureus } \\
\text { ATCC 43300 }\end{array}$ & $\begin{array}{c}\text { Enterococcus } \\
\text { faecalis } \\
\text { ATCC } 29212\end{array}$ & $\begin{array}{c}\text { Escherichia } \\
\text { coli } \\
\text { ATCC } 25922\end{array}$ & $\begin{array}{c}\text { Acinetobacter } \\
\text { baumannii } \\
\text { ATCC } 19606\end{array}$ \\
\hline Leaf EO & $14.0 \pm 0.6^{\mathrm{b}}$ & $16.4 \pm 0.7^{\mathrm{b}}$ & $9.4 \pm 0.4^{\mathrm{b}}$ & $8.2 \pm 0.2^{\mathrm{b}}$ \\
\hline Fruit EO & $13.5 \pm 0.5^{\mathrm{b}}$ & $15.3 \pm 0.6^{\mathrm{b}}$ & $8.8 \pm 0.3^{\mathrm{b}}$ & $8.2 \pm 0.2^{\mathrm{b}}$ \\
\hline GM & $0.016 \pm 0.001^{\mathrm{a}}$ & $0.064 \pm 0.004^{\mathrm{a}}$ & $0.004 \pm 0.0002^{\mathrm{a}}$ & $0.032 \pm 0.002^{\mathrm{a}}$ \\
\hline MS & $14.2 \pm 0.5^{\mathrm{b}}$ & $16.3 \pm 0.6^{\mathrm{b}}$ & $9.3 \pm 0.4^{\mathrm{b}}$ & $8.4 \pm 0.4^{\mathrm{b}}$ \\
\hline
\end{tabular}

EO, essential oil; GM, gentamicin; MS, methyl salicylate; for MIC values given in each column different superscript letters indicate significant differences between the mean values $(\mathrm{p}<0.05)$ in the Tukey's test

obtained from the Balkan (Serbian) population (undefined plant material, probably leaves or whole overground parts with leaves prevailing in the biomass) (9), the level of methyl salicylate was lower $(96.90 \%)$, and the concentration of accompanying constituents (monoterpenes) was higher than observed by us in the Polish leaf essential oil. Out of the eight monoterpenoid constituents, identified in the Serbian samples (9), such as limonene (2.17\%), $\alpha$-pinene $(0.22 \%), \beta$-pinene $(0.25 \%)$, sabinene $(0.08 \%), \beta$-myrcene $(0.09 \%)$, fenchone $(0.17 \%)$, and menthone $(0.12 \%)$, only the first four compounds were found in the Polish essential oil. In addition to the differences from the samples of Polish origin, the chemical profiles of essential oils from Asia and Balkans also differed significantly. This observation might imply a noticeable impact of environmental (climatic) cultivation conditions on chemical profiles of wintergreen oils. Although the subject requires more detailed studies, the GC-profile of the volatile fractions, especially in part of minor components, might be probably considered as a valuable tool for identification and authentication of the volatile fractions origin. In this context, the use of an additional polar capillary column in the present study (in lieu of a single non-polar one applied in the earlier works), which enabled us to characterize the GC-fingerprints in details might be recommended for this purpose.

To the best of our knowledge, the present work is the first that investigate the chemical composition of the essential oil of $G$. procumbens fruits. Apart from methyl salicylate, the fruit volatile oil was found abundant in aromatic and aliphatic alcohols with prevailing benzyl alcohol $(0.55 \%)$, heptan-2-ol $(0.07 \%)$, p-cymen-7-ol $(0.06 \%)$, and 4-methylhex5-en-2-ol $(0.02 \%)$, as well as in carboxylic acids represented mainly by 3-hydroxyphenylacetic acid $(0.39 \%)$, heptanoic acid $(0.37 \%)$, octanoic acid
$(0.08 \%)$, and nonanoic acid $(0.01 \%)$ (Table 1 , Figure 1B). In comparison to the leaf essential oil, the fruit volatile oil was distinguished by the presence of thirty eight specific volatiles, among which twenty compounds occurred in relatively high levels (not less than $0.01 \%$ ). This specific group contains a majority of the above listed dominant fruit volatiles (except for heptan-2-ol), as well as aliphatic and aromatic carbonyls (hexanal, pent-4-enal, furfural, benzaldehyde), 2-pentylfuran, eugenol, isoeugenol, methyl ester of 2,6-dihydroxybenzoic acid, isopinocarveol, dec-3-en-1-ol, and nonan-2-ol. Together with the selected typical leaf volatiles, these compounds might serve as analytical markers to differentiate between leaf and fruit essential oils of $G$. procumbens from Polish population.

Methyl salicylate, the dominant component of the analyzed wintergreen oils, is naturally found in several aromatic and non-aromatic plant materials, such as Betula lenta bark, Polygala senega roots, Filipendula ulmaria herb, and Viola tricolor herb (24). The compound primarily possesses antiinflammatory, analgesic, rubefacient and skin irritant activities. Ointments, liniments and therapeutic oils containing methyl salicylate are usually applied topically in human and veterinary medicine to relieve acute pain, related to lumbago, sciatica, strains, sprains, bruising, and various forms of rheumatism $(25,26)$. It is thought to penetrate the skin and underlying tissues (27), where it acts as an inhibitor of pro-inflammatory enzymes, such as cyclooxygenase and hyaluronidase, downregulates the expression of nitric oxide synthase and release of pro-inflammatory cytokines, such as IL- 6 and IL- $1 \beta$ $(8,28-30)$. The pure compound and methyl salicylate-rich wintergreen oils are also used as flavoring agents in chewing gums, shampoos, toilet soaps, and other toiletries, and are added to antiseptic mouthwash solutions and topical antifungal drugs (16). 
Moreover, wintergreen oils are often components of complex inhalation fluids, used as adjuvants for the treatment of upper and lower respiratory tract infections, sinus infections, rhinitis, and as wound healing agents as well. It is well established that the pharmacological activity of these preparations is based mainly on the ability to reduce inflammation $(8,30)$, but the antimicrobial properties of the essential oils might be also responsible for the observed therapeutic effects $(9,16)$. In the present study, we have documented high concentration of essential oils and methyl salicylate in leaves and, particularly, in fruits of G. procumbens cultivated in Poland, which, therefore, might be successfully used for the production of such preparations. On the other hand, there was no previous information on the antimicrobial activity of the fruit essential oil nor whether the differences observed in chemical profiles of wintergreen oils might influence their activity, which inspired us to explore the subject.

The antibacterial activity of the essential oils from leaves and fruits of $G$. procumbens was tested against twelve reference bacterial strains and bacterial colonies isolated from patients and the hospital environment. As summarized in Tables 2 and 3, the analyzed essential oils were active against all tested bacterial strains and isolates. Although MIC values obtained for the fruit essential oil were slightly lower than those for the leaf essential oil, the observed differences were not statistically significant ( $p>0.05)$, except the cases of clinical isolates of S. aureus (from pharynx) and E. faecalis (from urine). In general, with the MIC values ranging from 8.2 to $10.0 \mathrm{mg} / \mathrm{mL}$, Gram-negative bacteria were more susceptible to both essential oils than Grampositive ones (MIC values ranged from 13.2 to 16.7 $\mathrm{mg} / \mathrm{mL}$ ). Among the tested strains, A. baumanii (the reference strain, clinical isolate from sputum, and an environmental isolate) was found the most susceptible to the essential oils (MIC: $8.2-8.8 \mathrm{mg} / \mathrm{mL}$ ), while the strains of E. faecalis (all tested reference, clinical, and environmental samples) were the most resistant (MIC: 15.3-16.7 mg/mL). Both essential oils were relatively less effective than the standard antibiotic used in the study as a positive control the solution of gentamicin, a potent aminoglycosidic antibiotic, showed under the same analytical conditions MIC values in the range of $16.0-64.0 \mu \mathrm{g} / \mathrm{mL}$ and 4.0-32.0 $\mu \mathrm{g} / \mathrm{mL}$ against the tested Gram-positive and Gram-negative bacteria, respectively. On the

Table 3. MIC values of the leaf and fruit essential oils of G. procumbens against antibiotic-resistant clinical isolates and environmental bacteria.

\begin{tabular}{|c|c|c|c|}
\hline \multirow{2}{*}{$\begin{array}{l}\text { Clinical isolates and } \\
\text { environmental } \\
\text { bacteria }\end{array}$} & \multicolumn{2}{|c|}{$\mathrm{MIC}(\mathrm{mg} / \mathrm{mL})$} & \multirow{2}{*}{ Resistance to recommended antibiotics } \\
\hline & leaf EO & fruit $\mathrm{EO}$ & \\
\hline S. aureus (pus) & $14.1 \pm 0.5^{\mathrm{a}}$ & $14.1 \pm 0.5^{\mathrm{a}}$ & AN, CIP, DA, E, GM, K, SXT, TE, TOB \\
\hline S. aureus (pharynx) & $14.1 \pm 0.4^{b}$ & $13.2 \pm 0.4^{\mathrm{a}}$ & $\mathrm{DA}, \mathrm{E}, \mathrm{GM}, \mathrm{K}, \mathrm{TE}$ \\
\hline E.faecalis (urine) & $16.7 \pm 0.6^{b}$ & $15.5 \pm 0.4^{\mathrm{a}}$ & AM, C, CIP, GM, N/F, NOR TE, TGC \\
\hline E. faecalis (respirator) & $16.1 \pm 0.5^{a}$ & $16.4 \pm 0.4^{\text {a }}$ & AM, C, GM, P, RA, S, TE \\
\hline E. coli (wound) & $10.0 \pm 0.4^{a}$ & $9.7 \pm 0.4^{a}$ & $\begin{array}{c}\text { AM, AMC, C, CAZ, GM, CTX, FEP, NET, TE, } \\
\text { TIC, TIM, TOB, TZP, SXT }\end{array}$ \\
\hline E. coli (bronchia) & $8.8 \pm 0.3^{a}$ & $8.8 \pm 0.3^{a}$ & $\begin{array}{c}\text { AM, AMC, AN, C, CAZ, FOX, NET, PIP, TE, } \\
\text { TIC, SXT }\end{array}$ \\
\hline A. baumannii (sputum) & $8.5 \pm 0.3^{a}$ & $8.8 \pm 0.5^{a}$ & $\begin{array}{c}\text { AN, C, CAZ, CTX, FEP, GM, NET, PIP, TIC, } \\
\text { TIM, TOB, TZP, SAM, SXT }\end{array}$ \\
\hline A. baumannii (sink) & $8.5 \pm 0.4^{a}$ & $8.5 \pm 0.3^{a}$ & $\begin{array}{l}\text { AN, ATM, C, CAZ, CTX, DOR, ETP, FEP, } \\
\text { GM, IPM, MEM, NET, PIP, TIC, TIM, TOB, } \\
\text { TZP,SAM, SXT }\end{array}$ \\
\hline
\end{tabular}

EO, essential oil; AM, ampicillin (10 $\mu \mathrm{g})$; AMC, amoxicillin/clavulanic acid (20 mg/10 mg); AN, amikacin (30 mg); ATM, aztreonam (30 mg); C, chloramphenicol (30 mg); CAZ, ceftazidime (30 mg); CIP, ciprofloxacin (5 mg); CTX, cefotaxim (30 mg); DA, clindamycin $(2 \mu \mathrm{g})$; DOR, doripenem (10 mg); E, erythromycin (15 $\mu \mathrm{g})$; ETP, ertapenem (10 mg); FEP, cefepim (30 mg); FOX, cefoxitin (30 mg); GM,

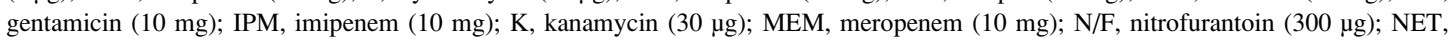
netilmicin $(30 \mathrm{mg})$; NOR, norfloxacin $(10 \mu \mathrm{g})$; P, penicillin $10 \mathrm{IU}$; PIP, piperacillin (100 mg); RA, rifampicin (5 $\mu \mathrm{g})$; S, streptomycin

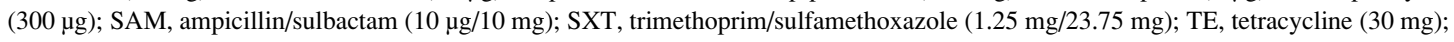
TGC, tigecyclin (15 mg); TIC, ticarcillin (75 mg); TIM, ticarcillin/clavulanic acid (75 mg/10 mg); TOB, tobramycin (10 mg); TZP, piperacillin/tazobactam $(100 \mu \mathrm{g} / 10 \mathrm{mg}$ ); for MIC values given in each row different superscript letters indicate significant differences between the mean values $(\mathrm{p}<0.05)$ in the Tukey's test. 
other hand, the activity of the essential oils against the reference strains did not differ significantly $(\mathrm{p}>$ 0.05 ) from their activity against the respective clinical and environmental isolates, which were found resistant to the recommended antibiotics used in clinical practice (Table 3). The prevailing presence of methyl salicylate in the essential oils explains similar MIC values, obtained for this compound and the examined volatile fractions (Table $2, \mathrm{p}>0.05$ ). These results also suggest a small effect of other components of the tested essential oils on their antimicrobial activity. In consequence, a similar activity might be expected for wintergreen oils produced from the plant materials of different origin.

Indeed, similar results in terms of antimicrobial potency were obtained by Hammer et al. (12), who examined the activity of various essential oils, including $G$. procumbens volatile oil from the herb (whole overground parts), against ten species of bacteria and fungi using an agar dilution method. The work reported higher antibacterial activity of wintergreen oil against reference strains of Gramnegative bacteria, i.e. Acinetobacter baumanii, Aeromonas sobria, Escherichia coli, Klebsiella pneumoniae, Salmonella typhi, Serratia marcescens, than against Gram-positive microorganisms, represented by Staphylococcus aureus and Enterococcus faecalis. A research conducted by Nikolić et al. (9) with the use of a microdilution method confirmed higher resistance of Gram-positive bacteria to the $G$. procumbens essential oil (distilled from undefined plant material, probably leaves or whole overground parts), and showed its bacteriostatic and bactericidal activity against numerous strains of oral bacteria, food spoilage microbes and pathogen fungi. Although the antibacterial activity of the essential oil against oral bacteria appeared to be noticeably lower (MIC values ranging between 0.6 and 3.00 $\mathrm{mg} / \mathrm{mL}$ ) than that of the positive antibiotic control (streptomycin, MIC: $0.05-0.20 \mathrm{mg} / \mathrm{mL}$ ), it was at least comparable to the capacity of two commercially available adjuvant preparations (mouthrinses), popularly used to treat bacterial infections of the upper respiratory tract, i.e. Hexoral ${ }^{\circledR}$ (composed of i.a. levomenthol, methyl salicylate, and essential oils of Mentha sp., Anis sp., Chamommila sp., Syzygium clove and Eucalyptus sp.; MIC: 0.19-3.12 mg/mL) and Tebodont ${ }^{\circledR}$ (composed of i.a. essential oil of Melaleuca alternifolia, limonene and linalool; MIC: 23.33-40.00 mg/mL) (9). On the other hand, Prabuseenivasan et al. (16) showed (with the use of a disc diffusion method) that the antibacterial activity of the closely related $G$. fragrantissima essential oil against strains of Bacillus subtilis, S. aureus, E. coli, K. pneumoniae, Pseudomonas aeruginosa, and Proteus vulgaris was lower than that of pure essential oils known as strong antiseptics, like cinnamon, lemon, rosemary, and clove essential oils. In a continuing research using an agar well diffusion method, Chaudhari et al. (31) pointed to the lack of antistreptococcal activity of commercially available G. fragrantissima essential oil against Streptococcus mutans reference strains (inhibition zone $=0.00$ $\mathrm{mm})$, in contrast to cinnamon $(12.51 \mathrm{~mm})$, lemongrass $(10.07 \mathrm{~mm})$, cedarwood $(7.42 \mathrm{~mm})$, clove $(6.60 \mathrm{~mm})$ and eucalyptus $(3.44 \mathrm{~mm})$ essential oils, that demonstrated strong antibacterial activity under the same analytical conditions.

Summarizing results of the present study and the earlier works mentioned above, it should be expected that wintergreen essential oils, abundant in methyl salicylate and obtained from various Gaultheria species, different plant parts and from plants cultivated in various geographical regions, might exhibit comparable therapeutic values. The value of the particular plant materials as sources of wintergreen oils may be thus well defined by the yield of the essential oil and methyl salicylate.

When it comes to antimicrobial properties, the relative low MIC values reported here for the essential oils from the leaves and fruits of G. procumbens against the tested bacterial strains in comparison to a positive antibiotic control do not diminish their potential use in the treatment of bacterial infectionsmediated diseases. Considering the broad activity spectrum of the major constituent (methyl salicylate) of the volatile fraction, they may appear to be most effective in reducing infection-related inflammation, but direct antibacterial action should be also taken into consideration as an additional benefit of their presence in multicomponent pharmaceutical preparations.

\section{CONCLUSIONS}

This is the first report on the chemical composition and biological activity of the essential oils isolated from the fruits and leaves of G. procumbens cultivated in Poland. The essential oils obtained in the hydrodistillation process are characterized by high yield and moderate antibacterial activity against selected pathogenic Gram-positive and Gram-negative bacteria, and this activity may be attributed to the presence of methyl salicylate, the major constituent of both essential oils. As valuable natural sources of this compound, the investigated essential oils from the Polish population of the plant demonstrate a great therapeutic potential, especially as components of 
medical preparations exhibiting not only anti-inflammatory and analgesic activity but also antibacterial properties. Moreover, considering high yield of the essential oils, their presence in leaves and fruits of $G$. procumbens may partly explain therapeutic applications of the plant materials in the treatment of bacterial infections-related inflammatory disorders, reported by traditional medicine.

\section{Acknowledgments}

The authors are grateful to the Medical University of Lodz for financial support (grant No. 503/3-022-01/503-31-001 and 502-03/3-02201/502-34-058). We thank Piotr Banaszczak from the Arboretum in Rogow, for authentication of the plant material and to Prof Danuta Kalemba from the Institute of General Food Chemistry, the Faculty of Biotechnology and Food Sciences of the Lodz University of Technology, for providing access to the GC-MS equipment.

\section{REFERENCES}

1. Burt S.: Int. J. Food Microbiol. 94, 3 (2004).

2. Bakkali F., Averbeck S., Averbeck D., Idaomar M.: Food Chem. Toxicol. 46, 446 (2008).

3. Orchard A., van Vuuren S.: Evid. Based Complement. Altern. Med. 2017, e4517971 (2017).

4. Ríos J.L., Recio M.C.: J. Ethnopharmacol. 100, 80 (2005).

5. Fabio A., Cermelli C., Fabio G., Nicoletti P., Quaglio P.: Phytother. Res. 21, 374 (2007).

6. Adorjan B., Buchbauer G.: Flavour. Frag. J. 25, 407 (2010).

7. Middleton D.J.: Bot. J. Linn. Soc. 106, 229 (1991).

8. Liu W.R., Qiao W.L., Liu Z.Z., Wang X.H., Jiang R. et al.: Molecules 18, 12071 (2013).

9. Nikolić M., Marković T., Mojović M., Pejin B., Savić A. et al.: Ind. Crop. Prod. 49, 561 (2013).

10. Todorović B., Potočnik I., Rekanović E., Stepanović M., Kostić M. et al.: J. Environ. Sci. Heal. B. 51, 832 (2016).

11. Ribnicky D.M., Poulev A., Raskin I.: J. Nutraceut. Function. Med. Foods 4, 39 (2003).

12. Hammer K.A., Carson C.F., Riley T.V.: J. Appl. Microbiol. 86, 985 (1999).
13. Kujur A., Kiran S., Dubey N.K., Prakash B.: LWT-Food Sci. Technol. 86, 132 (2017).

14. Pandey B.P., Thapa R., Upreti A.: Asian. Pac. J. Trop. Biomed. (article in press).

15. Pawar V.C., Thaker V.S.: Mycoses. 49, 316 (2006).

16. Prabuseenivasan S., Jayakumar M., Ignacimuthu S.: BMC Complement. Alternat. Med. 39, 6 (2006).

17. Nagendra Prasad M.N., Shankara Bhat S., Nivedita Dharwar V., Shraddha Mehta B., Chauhan A.: Arch. Phytopathol. Plant Protect. 44, 412 (2011).

18. Chopra R.N., Chopra I.C., Handa K.L., Kapur L.D.: Indigenous Drugs of India, pp. 179-181, Academic Publishers, Calcutta, India 1994.

19. Bantawa P., Da Silva J.A.T., Ghosh S.K., Mondal T.K.: J. Hortic. Sci. Biotech. 86, 479 (2011).

20. Vidic D., Maksimović M., Cavar S., Siljak-Jakovlev S.: Chem. Biodivers. 7, 1208 (2010).

21. Kiran S., Prakash B.: J. Agric. Food Chem. 63, 10518 (2015).

22. http://www.eucast.org/fileadmin/src/media/ PDFs/EUCAST files/Disk test documents/Version 5/Manual v 6.0 EUCAST Disk Test final. pdf (09.05.2018).

23. http://www.eucast.org/fileadmin/src/media/ PDFs/EUCAST files/Breakpoint tables/v 8.0 Breakpoint Tables.pdf (09.05.2018).

24. Pierpoint W.S.: Adv. Bot. Res. 20, 163 (1994).

25. Derry S., Matthews P.R., Wiffen P.J., Moore R.A.: Cochrane Database Syst. Rev. 11, CD007403 (2014).

26. Amann R., Peskar B.A.: Eur. J. Pharmacol. 447, 1 (2002).

27. Cross S.E., Anderson C., Roberts M. S.: Br. J. Clin. Pharmacol. 46, 29 (1998).

28. Zhang T., Sun L., Liu R., Zhang D., Lan X. et al.: Mol. Pharm. 9, 671 (2012).

29. Zhang D., Liu R., Sun L., Huang C., Wang C. et al.: Molecules 16, 3875 (2011).

30. Qin R.G., Long Q.D., Qin S.M., Zhou M.: Shizhen. Guoyi. Guoyao. (Shizhen Med. Mat. Med. Res.) 24, 409 (2013).

31. Chaudhari L.K., Jawale B.A., Sharma S., Sharma H., Kumar C.D., Kulkarni P.A.: J. Contemp. Dent. Pract. 13, 71 (2012).

Received: 23.05 .2018 